Nevertheless, a positive attitude for continued participation in the audit process was achieved, and we ultimately found the experience rewarding and educational.

ANISH BAHRA St George's Hospital, London SW17

VAL PRYDE NAHEED AHMAD NOAMI BRONZITE

SIAN HOWELL ONN MIN KON RICHARD SLACK Audit office,
St Albans City Hospital, St Albans AL5 $3 P M$

1 Firth-Cozens J, Storer D. Registrars' and senior registrars' perceptions of their audit activities. Quality in Health Care 1992;1:161-4.

\section{Jennifer's ear: airing the issues}

Dr Nick Black's editorial ${ }^{1}$ illustrates the disingenuousness of those seeking to confirm their prejudices. The case of Jennifer's ear has little to do with the provision of services for otitis media with effusion (OME) (glue ear). Her father recently explained that her problem was one of recurrent tonsillar infections for which she needed adenotonsillectomies, ${ }^{2}$ and that treatment of her ear condition was not of prime consideration. To base criticism of the current management of OME on this case is unwarranted.

The Effective Health Care bulletin advocates what practising otological surgeons already do in most instances for uncomplicated glue ear; those who ignore the current literature from their surgical peers $^{34}$ are unlikely to be convinced by a paper from non-clinicians. The performance of adenoidectomy as a day case is certainly feasible and the paper by Yardley ${ }^{5}$ considers this, but to say he has questioned the need for inpatient care is to overstate his conclusions. The audit to 1991 showing that many health districts fail to carry out grommet insertions as day cases $^{6}$ probably illustrates the shortcomings of data retrieval in the NHS at that time, since it has been impossible to separate those cases having grommet insertion as a single procedure from those having more extensive surgery such as adenotonsillectomy. For Black to suggest that had day case treatment been advised for Jennifer, she need not have waited for her operation is to confuse the length of an inpatient waiting list with the availability of day case surgery. Day case surgery requires exactly the same amount of operating time and sugeon availability and depends critically on access to an appropriate bed. Day case surgery does not necessarily eliminate waiting times and indeed may prolong waiting if day care facilities are limited.

The aspect of management of glue ear that remains largely ignored is the time it takes to see an otologist and to get reliable audiometry performed. This is in large measure a reflection of the paucity of paediatric otolaryngological services.

By the time most children are seen they have had established glue ear for a considerable time and have undergone a period of unwatchful waiting. Better and quicker access to competent audiometric assessment in a properly soundproofed environment is a prerequisite to better diagnosis and supervision of the hearing loss. Royal Hallamshire Hospital Sheffield Children's Hospital,
Sheffield

1 Black NA. Jennifer's ear: airing the issues. Quality in Health Care 1992;1:213-4.

Bennett J. Jennifer's story. Daily Telegraph 1993 Jan 11: 14.

3 Maw AR, Herod F Otoscopic, impedance and audiometric findings in glue ear treated by adenoidectomy and tonsillectomy: a prospective randomised study. Lancet 986;i:1399-402.

4 Maw AR, Parker A. Surgery of the tonsil and adenoids in relation to secretory otitis media in children. Acta Otolaryngol (Stockh) 1988;454:202-7.

5 Yardley MPJ. Tonsillectomy, adenoidectomy and adenotonsillectomy: are they safe day case procedures? 7 Laryngol Otol 1992; 106:299-300.

6 Audit Commission. All in a day's work: an audit of day surgery in England and Wales. London: HMSO, 1992. (NHS occasional paper, No 4.)

AUTHOR's REPLY - Putting aside the particular diagnosis which prompted the political debate, I do not in any way alter my views of the current management of glue ear, which remains an area of public and professional concern. The Audit Commission, which performed the audit of day surgery in 1991, was well aware of the shortcomings of the hospital episode system and therefore did not rely on it, as explained in the report $\mathrm{Mr}$ Bull quotes. ${ }^{1}$ One of the several advantages of day surgery is that it is considerably cheaper than inpatient care. The resources released can be redeployed to reduce the time patients are currently having to wait. One use of such resources could be audiometry services, thus reducing waiting times for investigations of middle ear functioning.

NICK BLACK
Department of Public Health and Policy Health
Services Research Unit,
London School of Hygiene and Tropical Medicine,
London
WC1E 7HT
1 Audit Commission. All in a day's work: an audit
of day surgery in England and Wales. London:
HMSO, 1992. (NHS occasional paper, No 4.)

\section{Clinical audit project}

The clinical audit project is concerned with the development of audit in four therapeutic professions: clinical psychology, occupational therapy, physiotherapy, and speech and language therapy. Commissioned by the Department of Health, the work is being carried out by experienced social science researchers and policy analysts in health studies from two units: Maurice Kogan and Tim Packwood from the Centre for the Evaluation of Public
Policy and Practice, Brunel University, and Sally Redfern, Sarah Robinson, Ian Norman, and Anémone Kober from the Nursing Research Unit, King's College, University of London.

The aim of the project is to work with the four professions to develop and evaluate a set of models on which their audit activities could be based. The models are likely to contain components specific to each profession as well as a common core, and they will constitute a logical development of the work undertaken by Professor Charles Normand and colleagues that advocated a common framework for audit in these four professions. ${ }^{1}$

The project's current phase - interviewing key people with knowledge of audit in these professions, selecting case studies, and devising interview schedules - is almost complete. The next phase will comprise, for each case study, interviews with people in each profession who are involved in audit activities and with members of other professions or groups whose work may impact on these activities. The data will be analysed to identify generic and specialist principles and components of audit and those issues in which there is agreement or disagreement within and between the four professions. The aim will be to produce a detailed set of draft models for audit practice for discussion with the professions.

Any enquiries about the project should be addressed to Anémone Kober, Nursing Research Unit, King's College, Waterloo Road, London SE1 8TX (tel 071872 3060/3057; fax 0718723069 ).

\section{Centre for the Evaluation of Public Policy and KOGAN Policy and Practice, Brunel University, Uxbridge Middlesex \\ SALLY REDFERN Nursing Research Unit King's College, Waterloo Road London SE1 8TX \\ 1 Normand C. Clinical audit in professions allied to medicine and related therapy professions. Belfast: Health Care Research Unit, Queen's University, 1991. (Report to the Department of Health on a pilot study.) \\ BOOK REVIEWS}

Evaluation Medicale des Soins Hospitaliers. Alexandra Giraud (pp 210 Ffr 250). Paris: Economica, 1992. ISBN 2-7178-2335-2

Alexandra Giraud wants hospital doctors in France to take charge of the evaluation of medical practice rather than submitting to it as an external constraint. Medically qualified, with degrees in politics (Paris) and public health (Yale), she was responsible from 1987 to 1990 for the Service for the Evaluation of Health Care 